\title{
An Exploratory Investigation Of The Impact Of National Culture On Motivation And Learning Styles Of B-School Students From India
}

Suresh Gopalan, DBA, Winston Salem State University, USA Moula Cherikh, PhD., Winston Salem State University, USA Mak Khojasteh, DBA, Winston Salem State University, USA

\begin{abstract}
India has emerged as one of the fastest growing economies in the world. Business magazines and newspapers routinely refer to India as an emerging global powerhouse along with Brazil, China, and Russia (commonly referred to as the BRIC economies). The Indian GDP has experienced a real growth of 8.9 percent from 2003-2007 and is projected to grow by 7.1 percent in 2009 and 7.5 percent in 2010. India's GDP was US\$911 billion in 2007 (data obtained from Economist.com and EconomyWatch.com). The rapid economic growth rate can be attributed to the following three factors: 1) deregulation policies adopted by the Indian government in the early 1990s, 2) dynamics of globalization, and 3) ever advancing capabilities of the Internet and other forms of telecommunication.
\end{abstract}

Keywords: Motivation; Intrinsic Rewards; Extrinsic Rewards; Business Education; India

\section{INTRODUCTION}

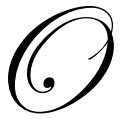

ver the last decade, several multinational firms have established a substantial presence in India. At the same time, many Indian firms have significantly expanded their domestic and international presence to take advantage of robust growth in international and domestic markets (Krebsbach, 2007). These twin factors have created a tremendous demand for large numbers of well-trained highly qualified graduates to staff thousands of well-paying jobs. India's educational infrastructure has the responsibility of producing highly skilled graduates who are trained for executing knowledge and research-intensive work. However, as noted in the Economist Intelligence Unit (2006), while India produces more university graduates than any English speaking country, there are looming concerns that there are fewer high-quality graduates with the requisite skill-sets who are readily employable. According to Kuruvilla and Ranganathan (2008), demand for graduates exceeds supply and there is a critical shortage for business graduates with the right skill sets.

\section{HIGHER EDUCATION IN INDIA: SOME OBSERVATIONS FROM THE FIELD}

HR experts lament that while more than 18,000 colleges and universities in India enroll around 11 million students, only a small percentage of them have received a level of education that equips them with critical thinking skills, self-learning, desire for personal development, and a need for achievement. Indian students are exposed to a rigorous educational system, but as noted by Giridharadas (2008):

The problem....lies in a classroom environment that infantilizes students well into their mid-20s, emphasizing silent note-taking and discipline at the expense of analysis, debate, and persuasion..... what the market wants and the school provides are totally different. 
He cites a study published in 2007 which concluded that only 10 percent of Indian graduates with generalist degrees were considered employable by top employers compared to 35 percent of graduates with engineering degrees.

Similar observations are made in an assessment by Economist Intelligence Unit (2006) in that the curriculum encourages memorization and does not nurture analytical, intellectual, communication and interpersonal skills - all of which are required to be successful in the job market. Performance is almost exclusively based on examination scores (Kuruvilla and Ranganathan, 2008).

Large numbers of students in classrooms make it difficult for faculty members to interact extensively with their students or engage them in extensive question-and-answer sessions. By default, the lecture method has become the most preferred method of instruction. Students' academic motivation comes from a desire to pass the examinations and to obtain work. Lecturers' instruction styles too often reinforce the goal of passing examinations (Chitnis, 2000).

Damast (2008) cites the results of a study sponsored by the Associated Chambers of Commerce and Industry of India (Assocham) that has reached several important conclusions. Although India has more than 1,600 business schools offering bachelors and graduate degrees, the academic quality is perceived to be uneven. According to study's author Jyoti Bhutani, a clear demarcation exists between the quality of faculty who teach in the top business schools in India compared to the rest of the faculty who are teaching in other institutions. The study notes that a significant number of business faculty are under-prepared and uninformed of current national and international economic trends and business conditions. Consequently, educational institutions in the second and third tier levels often turn out graduates with varying levels of quality (Giridharadas, 2008). This results in a substantial salary differential between graduates from top Indian business schools and the remaining institutions.

These findings raise several critical questions:

- What insights do we have about current academic environments?

- What kind of future employees are being produced by Indian business schools to meet the challenges of the rapidly growing Indian economy?

- What are the prevalent teaching styles in various classrooms?

- $\quad$ Is the curriculum imparting the right skills to future graduates?

- How important is the role of the teacher in setting the right tone in class?

It is important to obtain answers to these questions as it will help Indian business schools to refine/improve their pedagogical techniques to sustain the competitive advantage enjoyed by the country. Students are customers of education and it is important to obtain their opinions on all aspects of their higher education experience (Sakthivel and Raju, 2006). Besides academic stakeholders, future employers will be able to gain insights about how students are motivated and their preferred learning styles (Hill, Lomas, and MacGregor, 2003). In turn, a meaningful dialogue between academics and industry practitioners will help to bridge existing gaps between industry expectations and classroom environments. Therefore, this study is being conducted to obtain insights about motivation and learning styles of Indian students who are majoring in business. Also included in this study is an assessment of the role of the teacher (lecturer) in influencing the motivation/learning styles of their students.

\section{METHODOLOGY}

A 33-item survey instrument was administered to business students who were in their third year of completing their B.Com degree in two private colleges in Chennai, India. The survey instruments were distributed and collected through the cooperation of faculty members and the department heads. Respondents were requested to remain anonymous; no names or other forms of identification were collected. Respondents were required to respond to each statement using a 5-point Likert scale where $1=$ strongly agree, 2=agree, 3=neutral, 4=disagree, and $5=$ strongly disagree. 
The 33 items included in the survey are based on Herzberg's two-factor theory of motivation which advocated the notion of intrinsic factors (e.g., love for the work itself, desire to achieve, desire to grow) and extrinsic factors (e.g., salary, relationship with supervisors and peers, etc.) that impact motivation (1999). While Herzberg's motivation framework dealt with respondents' perception about their workplace, the overall notion of intrinsic and extrinsic factors have been studied in a number of other environments and in many countries including India and were deemed appropriate for this study (Nair and Ghosh, 2006; Mahesh and Kasturi, 2006; Mehta, Armenakis, Mehta, Irani 2006). The researchers generated 13 statements that measured intrinsic motivation and 20 statements that reflected extrinsic motivation.

Examples of statements that measure intrinsic motivation include:

- I Itudy because I enjoy learning. (item \#17)

- $\quad$ I believe I am capable of learning the subject. (item \#19)

- When it comes to learning, I set high expectations for myself. (item \#20)

The student who loves to learn and who aspires to excel or achieve is analogous to a worker who loves his/her work and has a high motivation to excel. Achievement and love for work are all considered as intrinsic factors of motivation which are part of job content (Herzberg, 1999).

Examples of statements that reflect extrinsic factors of motivation include:

- $\quad$ Lecturers set high expectations for this course. (item \#18)

- $\quad$ I have the opportunity to express my point of view. (item \#23)

- $\quad$ My lecturers are interesting. (item \#27)

The role of the teacher is analogous to the role of the supervisor in an organization who is instrumental in impacting overall organizational atmosphere and disbursements of rewards and punishments (all part of job context). When students are rating their lecturers' teaching styles, class assignments and opportunities to participate in class, they are responding to extrinsic factors.

A total of 452 useable surveys were obtained. Of these, 334 (74\%) were women and 118 (26\%) were men. The average ages for female and male students were 19.4 and 20.2 years, respectively. Overall average family income was Rs. 1,33,505 per annum. The majority of students were not employed; $94 \%$ of female respondents and $78 \%$ of male respondents indicated that they were not working. With respect to parents' education, $53.1 \%$ said that their parents had not attended college (i.e., parents' highest education was high school or less). In other words, these respondents were the first ones to attend college from their family. Both genders identified "to learn and get a job" as the \#1 reason for attending college (51.6\% of the overall sample). Parental funding was the primary source of paying for college education-91\% of women and $68 \%$ of men indicated that their education was financed by their parents. Tables 1-5 show more detailed information about the sample demographics.

Table 1: Breakdown by Gender

\begin{tabular}{|l|c|c|}
\hline & Number of responses & \multicolumn{2}{|c|}{ Percentage } \\
\hline Male & 118 & 26 \\
\hline Female & 334 & 74 \\
\hline Total & 452 & 100 \\
\hline
\end{tabular}

Table 2: Breakdown by Age

\begin{tabular}{|l|c|c|c|c|c|c|}
\hline & $\begin{array}{c}\text { Number of } \\
\text { Responses }\end{array}$ & Minimum & Maximum & Median & Mean & $\begin{array}{c}\text { Standard } \\
\text { deviation }\end{array}$ \\
\hline Male & 116 & 18 & 32 & 20 & 20.2 & 1.6 \\
\hline Female & 327 & 18 & 23 & 19 & 19.4 & 0.8 \\
\hline Total & 443 & 18 & 32 & 19 & 19.6 & 1.5 \\
\hline
\end{tabular}

$* 9$ respondents did not indicate their age 
Table 3: Family Income per Annum (in Rupees)

\begin{tabular}{|c|c|c|c|c|c|}
\hline $\begin{array}{c}\text { Number of } \\
\text { Responses }\end{array}$ & Minimum & Maximum & Median & Mean & $\begin{array}{c}\text { Standard } \\
\text { deviation }\end{array}$ \\
\hline 374 & 1000 & $1,200,000$ & 50,000 & 133,507 & 146,343 \\
\hline
\end{tabular}

* 78 respondents did not provide information about family income

Table 4: Parents' Education

\begin{tabular}{|l|c|c|}
\hline & Number of responses & Percentage \\
\hline College & 207 & 46.9 \\
\hline Non-College & 234 & 53.1 \\
\hline Total & 441 & 100 \\
\hline
\end{tabular}

* 11 respondents did not provide information about their parents' education

Table 5: Reasons for Attending College (Question \#12 on the Last Page of the Survey)

\begin{tabular}{|l|l|l|l|l|l|l|l|}
\hline & & To Learn & To get a job & $\begin{array}{c}\text { To learn and } \\
\text { get a job }\end{array}$ & $\begin{array}{c}\text { To advance } \\
\text { my career }\end{array}$ & Don't know & Total* \\
\hline \multirow{2}{*}{ Male } & \# Responses & 21 & 19 & 73 & 38 & 4 & 155 \\
\cline { 2 - 9 } & Percent & 13.5 & 12.3 & 47.1 & 24.5 & 2.6 & 100 \\
\hline \multirow{2}{*}{ Female } & \# Responses & 49 & 32 & 233 & 119 & 5 & 438 \\
\cline { 2 - 9 } & Percent & 11.2 & 7.3 & 53.2 & 27.2 & 1.1 & 100 \\
\hline \multirow{2}{*}{ Total } & \# Responses & 70 & 51 & 306 & 157 & 9 & 593 \\
\cline { 2 - 9 } & Percent & 11.8 & 8.6 & 51.6 & 26.5 & 1.5 & 100 \\
\hline
\end{tabular}

*Total number of responses is higher than the number of respondents because some students identified more than one reason for learning

Cronbach's alpha reliability coefficient was used to test the reliability of the survey instrument. It is a test reliability technique that requires only a single test administration to provide a unique estimate of the reliability for a given test (Gliem and Gliem, 2003). The closer the alpha coefficient is to 1, the greater is the internal consistency of items in the scale. A Cronbach's alpha of .891 was obtained indicating that the instrument had good reliability.

Figure 1: Factor Analysis-Scree Plot

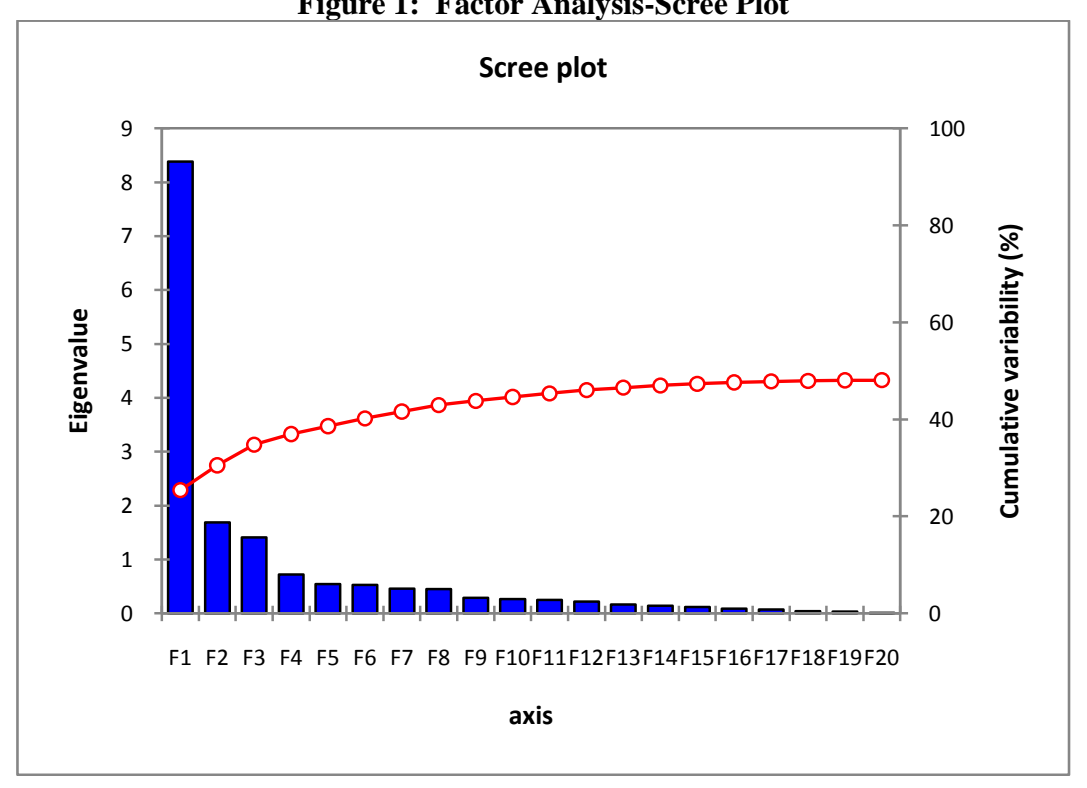

Given the exploratory nature of this study, a principal component factor analysis was done to identify patterns in the data. Second, varimax orthogonal rotation was used to explore whether the 33 items were made up of distinctive groupings (factors). After rotation, two factors emerged that explained 23.07 and 7.44 percent of variance 
in the data (cumulative variance is 30.51). Cronbach's alpha for the first factor was .91 and the second factor was .60. Seventeen items loaded on the first factor and five items loaded on the second factor. We stopped here as the next factor accounted for an additional 4 percent of the data variance (Figure 1 and Table 6). Items that had an absolute loading of more than .40 were included for consideration. We labeled the first factor as Lecturer's role and the second factor as Desire to excel/achieve (Table 7).

Table 6: Factor Analysis

\begin{tabular}{|l|c|c|}
\hline & F1 & F2 \\
\hline Variability & 23.07 & 7.44 \\
\hline Cumulative & 23.07 & 30.51 \\
\hline
\end{tabular}

Table 7

Factor 1 - Lecturer's Role (Extrinsic Motivation)

Factor 2 - Desire to Excel/Achieve (Intrinsic Motivation)

\begin{tabular}{|c|c|c|c|c|c|c|}
\hline Item & Factor 1 & Mean & SD & & & \\
\hline \#28 My lecturers are enthusiastic & .803 & 2.69 & 1.08 & & & \\
\hline \# 27 My lecturers are interesting & .768 & 2.64 & 1.09 & & & \\
\hline $\begin{array}{l}\text { \# } 33 \text { My lecturers regularly encourage me to participate and express } \\
\text { my opinions }\end{array}$ & .746 & 2.33 & 1.06 & & & \\
\hline \# 25Lecturers seeks and listen to my suggestions & .729 & 2.74 & 1.04 & & & \\
\hline \# 29 My lecturers are caring & .726 & 2.28 & 1.09 & & & \\
\hline \# 31 My lecturers use varieties of instructions techniques & .703 & 2.63 & 1.01 & & & \\
\hline \# 7 My lecturers encourage creative thinking & .685 & 2.30 & 1.05 & & & \\
\hline \# 30 My lecturers are knowledgeable about the subject matter & .670 & 2.12 & .97 & & & \\
\hline \# 23 I have the opportunity to express my point of view & .644 & 2.18 & .92 & & & \\
\hline \# 32 My lecturers let me know why we are studying assigned topics & 619 & 2.42 & .96 & & & \\
\hline $\begin{array}{l}\text { \#26 Every time I attend class sessions, I feel that's my course, my } \\
\text { session, and my time }\end{array}$ & .558 & 2.54 & 1.01 & & & \\
\hline \#5 My course assignments are clear & .500 & 2.17 & .80 & & & \\
\hline \#3 My course assignments are interesting & .496 & 2.36 & .98 & & & \\
\hline \#14 Lecturers give credit for anything I do in their courses & .478 & 2.8 & 1.02 & & & \\
\hline $\begin{array}{l}\text { \# 24 Lecturers allow me to choose the topics of assignments based on } \\
\text { my interest }\end{array}$ & .494 & 3.26 & 1.17 & & & \\
\hline \#10 I am allowed to do things differently in the courses & .490 & 2.84 & 1.05 & & & \\
\hline \#4 My course assignments require a great deal of thinking & .443 & 2.50 & 1.04 & & & \\
\hline & & & & Factor 2 & Mean & SD \\
\hline \#20 When it comes to learning I set high expectations for myself & & & & .502 & 1.91 & .83 \\
\hline \#15 My main focus in a course is to get the marks that I want & & & & .470 & 2.12 & 1.09 \\
\hline \#21 I believe I can pass the course with marks I want & & & & .450 & 1.65 & .70 \\
\hline $\begin{array}{l}\text { \#22 I believe I am capable of utilizing whatever I lean in the courses } \\
\text { for my career }\end{array}$ & & & & .432 & 1.88 & .81 \\
\hline \#19 I believe I am capable of learning the subjects & & & & .420 & 1.53 & .62 \\
\hline
\end{tabular}

Columns 1 and 4: Factor pattern after Varimax rotation

\section{DISCUSSION OF RESULTS}

There are several key points worthy of discussion. First, these results reveal the paramount importance of the faculty member's contribution to their students' overall motivation and learning style. The first factor labeled as Lecturer's role shows that students have high expectations of their faculty members to (a) exhibit certain specific behaviors (caring, enthusiastic, interesting, knowledgeable in subject matter etc.) and (b) to create a classroom atmosphere where relevant assignments, active student participation and involvement are allowed. A reasonable inference that could be made is if a faculty member is able to demonstrate the above mentioned behaviors and create a participative atmosphere in class, he/she will be effective in motivating their students. 
On one hand, this result partially supports the notion that Indian students are inclined to display extrinsic motivation patterns that reflect the contours of family and societal cultural values (Kakar, 1978; D. Sinha, 1998; J.B.P. Sinha, 1990). But a closer look also reveals a desire to "reduce" the high power distance that is characteristic of Indian culture. Students are seeking a classroom atmosphere that combines a two-way style of communication in conjunction with creative and independent thinking. Lecturers in India need to add variety to their pedagogical approach to prepare their graduates to assume leadership positions in a competitive global market.

The second factor, Desire to excel/achieve, shows that Indian students are also motivated by intrinsic factors. More importantly, they believe that they can achieve desired outcomes clearly revealing a preference for being "inner-directed" (Trompenaars, 1993). This pattern of thinking reflects a distinctive shift from traditional Indian values that reinforce a sense of dependence and subjugation to nature orientation (Gopalan and Rivera, 1997). Of the 33 items in the survey, respondents expressed the highest degree of agreement for the following item: $I$ believe I am capable of learning the subjects ( 1.53 on a 5 point scale). This was true for both male and female respondents (1.61 and 1.5 respectively).

It is interesting to note that despite the fact that over 50 percent of the sample was "first generation attending college", the self-confidence in their own ability to achieve is heartening. Students have expressed an interest to have an opportunity to enhance the "soft-skills" required by industry, such as communication, independent thinking, and participative skills that are critical for success in the Indian corporate environment.

\section{CONCLUSION AND IMPLICATIONS FOR FUTURE RESEARCH}

Our sample was obtained from two colleges located in Chennai. If results can be extrapolated to the country, data has to be collected from multiple locations and from a larger sample of business students. Second, the business students included in the sample were enrolled in business programs that were aided by the government (their tuition was subsidized). The study did not include business students who were paying the full tuition amount (no government subsidy). The latter group should be included in future studies.

Overall, business students respond well to a combination of extrinsic and intrinsic factors. While the results support the traditional importance given to the teacher's role in Indian culture, the type of teacher (lecturer) sought is clearly different! Business students expect faculty members who encourage active participation from students, seek their opinions and provide ample opportunities for expressing their thoughts. Students are also seeking faculty who are well versed in their fields who come to class with a sense of energy and enthusiasm.

Educational institutions should pay heed to student feedback. It is quite clear that business students are pushing back on rote learning, memorization, and conformity. Instead, they are seeking environments that hone their individual thinking and self-expression. An important implication is that educational institutions should devote additional resources to improving and enhancing faculty skill-sets. If much needed changes have to take place in the classroom, it starts with the faculty members. After all, the quality of graduates to a large extent depends upon the quality of faculty deployed in the classroom.

Cultures and dominant values do not change quickly. While we acknowledge the desire of Indian business students (at least from this sample) to create a classroom environment that is more typical of Western culture, it may not be a definite indicator of a permanent shift in values. Rather, it represents the inherent dynamics of a society that is experiencing the tension of blending traditional and imported values and thought patterns.

\section{AUTHOR INFORMATION}

Suresh Gopalan, Associate professor of Management is currently serving as the interim Associate Dean in the School of Business and Economics at Winston-Salem State University from 2004. He received a B.Com. from Loyola College, University of Madras; a MBA from the University of Southern Mississippi; and a DBA from Louisiana Tech University. His teaching, research, and consulting interests are in the areas of cross-cultural management, strategy, and ethics. He has published in a number of journals including Organization Studies, Journal of International Business Research, SAM Advanced Management Journal, Journal of Business Strategies, International Journal of Organizational Analysis, etc. 
Moula Cherikh is a professor of Operations Management in the School of Business and Economics, WinstonSalem State University. He received an $\mathrm{MS}$ and a $\mathrm{PhD}$ in operations research from Case Western Reserve University. Dr. Cherikh's teaching and research interests are in the areas of operations management, decision analysis, and optimization. His research work has been published in a variety of journals, including the Journal of the Operational Research Society, IEEE Transactions on Information Theory, International Journal of Services and Standards, International Journal of Operational Research, and International Journal of Information and Operations Management Education.

Mak Khojasteh is a professor of Management in the School of Business and Economics at Winston Salem State University in NC. He received a MBA from Iowa State University and D.B.A from United States International University with concentration in Management. His areas of teaching and research are motivation, job satisfaction and talent management. His research includes a textbook in Managing Workforce Diversity and articles published in variety of business journals such as; Public Personnel Management, International Journal of Public Administration, Journal of Management Studies, Journal of Global Competitiveness, Journal of Business and Economic Research, and Journal of College Teaching and Learning

\section{REFERENCES}

1. Chitnis, S. (2/3/2000). Higher Education in India. Black Issues in Higher Education, 16(25), retrieved online on 10/27/2008 from Ebsco Host data base.

2. Damast, A. (6/4/2008). India's Business Schools Need an Upgrade. Business Week Online 00077135.

3. Economist.com./countries/India. Retrieved on-line on 11/23/2008.

4. Economist Intelligence Unit Limited (2006). When a billion people are not enough; India's looming skills gap undermines its growth prospects. 7 .

5. Economywatch.com/indianeconomy. Retrieved on-line on 11/23/08.

6. $\quad$ Elliott, J. (July 25, 2005). Great Expectations. Fortune, 152(2), 78.

7. Giridharadas, A. (November 27, 2006). In India's higher education, few prizes for $2^{\text {nd }}$ place; Beyond world of elite schools, graduates enter work force with few prospects. The International Herald Tribune. Retrieved from Lexisnexis data base on 10/24/2008.

8. Gliem, J. A. and Gliem, R. R. (2003). Calculating, Interpreting, and Reporting Cronbach's Alpha Reliability Coefficient for Likert-Type Scales. Midwest Research to Practice Conference in Adult, Continuing, and Community Education.

9. Gopalan, S., and Rivera, J. (1997). Gaining a perspective on Indian value orientations: Implications for Expatriate Managers. The International Journal of Organizational Analysis, 5(2), 156-179.

10. Herzberg, F., Mausner, B., and Snyderman, B. B. (1999). The Motivation to Work. Transaction Publishers: New Brunswick (USA).

11. Hill, Y., Lomas, L., and MacGregor, J. (2003). Students' Perceptions of Quality in Higher Education. Quality Assurance in Education, 11(1), 15-20.

12. Kakar, S. (1978). The inner world: A psychoanalytic study of childhood and society in India. Oxford University Press: New Delhi.

13. Krebsbach, K. (2007-January). Inside the outsourcing world of India. Bank Technology News. 26-29.

14. Kuruvilla, S., and Ranganathan, A. (2008). Economic Development Strategies and Macro and Micro-level Human resource policies: The Case of India's "Outsourcing” Industry. Industrial and Labor Relations Review, 62(1), 39-72.

15. Mahesh, V. S., and Kasturi, A. (2006). Improving call centre agents' point of view: A UK-India study based on the agents' point of view. International Journal of Service Industry Management, 17(2), 136-157.

16. Mehta, A., Armenakis, A., Mehta, N., and Irani, F. (2006). Challenges and Opportunities of Business Process Outsourcing in India. Journal of Labor Research. 27(3), 323-338.

17. Nair, S. K., and Ghosh, S. (2006; July-September). Managerial work values in India: A Comparison among four industry sectors. South Asian Journal of Management, 13(30), 45-58.

18. Sakthivel, P. S., and Raju, P. (2006). An Instrument for Measuring Engineering Education Quality from Students' Perspective. The Quality Management Journal, 13(3), 23-34. 
19. Sinha, D. (1998). Basic Indian Values and Behavior Dispositions in the Context of National Development: An Appraisal. In D. Sinha and H. S. R. Kao (Eds.) Social Values and Development: Asian Perspectives (pp. 31-55). Sage: New Delhi.

20. Sinha, J. B. P. (1990). Work Culture in the Indian Context. Sage: New Delhi.

21. Trompenaars, F. 1993). Riding the Waves of Culture: Understanding Cultural Diversity in Business. Nicholas Brealey: London.

\section{NOTES}

